REVISTA ANDALUZA DE ANTROPOLOGÍA.

NÚMERO 4: ENCRUCIJADAS PARA LAS SOCIEDADES PESQUERAS DEL SUR EN EL MARCO DE LA GLOBALIZACIÓN. MARZO DE 2013

ISSN 2174-6796

[pp. 33-54]

http://dx.doi.org/10.12795/RAA.2013.i04.03

\title{
DEL PATRIMONIO NATURAL DE LOS PECES AL PATRIMONIO CULTURAL DEL PESCADO: EL ESPAI DEL PEIX DE PALAMÓS*
}

\section{Juan-Luis Alegret \\ Universitat de Girona}

\section{Resumen.}

Mediante la breve presentación de un ejemplo de proceso de producción patrimonial en el ámbito marítimo-pesquero intentamos mostrar de qué modo, entre los diferentes procesos de producción patrimonial marítima que se están produciendo actualmente en Palamós (Cataluña, España), existen diferentes "lógicas" que guían esos procesos, y que están provocando una verdadera transformación del concepto patrimonio marítimo así como de las prácticas a él asociadas.

Palabras clave: Antropología de la pesca, Patrimonio Cultural, Patrimonio Marítimo, Turismo cultural.

\footnotetext{
Abstract.

By submitting a brief example of the production process in the maritime heritage and fishing, we try to show that, among the different maritime heritage production processes that are occurring today in the Costa Brava (Catalonia, Spain), different "logics" are guiding these processes, which are causing a real transformation of the concept of maritime heritage and practices associated with it.

* Este trabajo se inscribe dentro del proyecto de investigación del Plan Nacional de Investigación I+D+i Patrimonio Etnológico, Sociedad y Cultura Marítima, PESCUM (HAR 2010-15566), financiado por el Ministerio de Economía y Competitividad (2010-2013)
} 
Keywords: Anthropology of fishing, Cultural Heritage, Maritime heritage, Cultural Tourism.

\section{INTRODUCCIÓN}

El principal peligro de la gran transformación que se está produciendo en el campo del patrimonio marítimo a raíz de la actual crisis económica, sería el de la mercantilización de la cultura marítima. Esta transformación, en parte se produce a través de la irrupción de la cultura marítima en el mercado de consumo cultural de masas, de la mano del turismo cultural, y muy especialmente del turismo gastronómico. Sin embargo, la producción simultánea de diversos ámbitos patrimoniales marítimos -tales como el patrimonio pesquero, el patrimonio submarino, el patrimonio histórico marítimo-, nos muestra que la situación es mucho más compleja y que el hecho de hacer una lectura reduccionista estrictamente economicista no nos ayuda a la comprensión global del fenómeno, y menos a apuntar su futuro.

Es evidente que la gastronomía como parte integrante del patrimonio cultural inmaterial de nuestras sociedades se está incorporando cada vez más activamente a las políticas culturales de patrimonialización (González, 1997) desarrollo local y promoción del turismo. En este sentido, a través del ejemplo elegido, nos proponemos mostrar de qué modo, en el proceso de producción patrimonial que se está realizando en el nuevo equipamiento cultural del Espai del Peix de Palamós, la creación de un nuevo objeto patrimonial conocido como el pescado de poco precio, sigue una lógica que se aleja de las formas tradicionales de puesta en valor que han caracterizado a los procesos de patrimonialización. En este sentido nos proponemos mostrar que no se trata solo de recuperar el valor patrimonial de ciertas especies de peces, crustáceos o mariscos, de las artes de pesca -técnicas y saberes de los pescadores asociados a su captura- y de la gastronomía utilizada para su preparación y consumo, sino que de lo que se trata es de crear un conjunto de elementos patrimoniales nuevos, que no existían anteriormente como patrimonio sino como cultura de los pescadores y sus familias.

Para ello mostraremos de qué modo opera este proceso de patrimonialización, que actúa simultáneamente sobre los ámbitos patrimoniales de orden natural -patrimonio natural: especies, caladores de pesca, fondos marinos, etc.- y orden cultural -patrimonio inmueble, mueble e intangible asociado a la pesca como actividad socio-cultural-(Pereira, 2009). Para ello pondremos de relieve que este proceso tiene como objetivo último la singularización, valorización y protección de un tipo concreto de especies marinas, la forma de pescarlas y sobre todo, la forma de cocinarlas y consumirlas: el pescado de poco precio. Sin olvidar que en última instancia es esa cualidad de tener poco precio, de estar poco valoradas en la subasta diaria del pescado, lo que ha llevado a la puesta en 
marcha de unas estrategias de patrimonialización puestas al servicio del sector pesquero profesional con el objetivo de ayudar a mejorar sus ingresos mediante la revalorización de esas especies. Es así como el valor añadido económico que se espera dar a esas especies corresponde al valor patrimonial cultural que se les reconoce e incorpora en el Espai del Peix como instancia patrimonializadora.

\section{PATRIMONIALIZACIÓN Y PROCESOS DE PRODUCCIÓN PATRIMONIAL}

En el sistema económico imperante, los conceptos culturales juegan cada vez más el papel de instrumentos ideológicos. La cultura ya ha pasado a formar parte de esta nueva economía cultural política (Appadurai, 2001) y es así como la patrimonialización de la cultura nos aparece como una nueva y reciente modalidad de producción cultural. Pero cultura y patrimonio no son lo mismo.

Nuestra sociedad se encuentra actualmente sometida a procesos constantes de cambio cultural y de promoción turística. La cultura es la fuente de la que bebe el patrimonio, pero la cultura, sometida a un proceso de producción patrimonial puede llegar a cosificarse, a transformarse en un objeto que como tal es pensado y manipulado. Es así como la cultura puede llegar a separarse de las personas, quedando desvinculada de la vivencia ahora ya bajo la denominación de patrimonio.

Cuando la cultura es presentada y representada como patrimonio, o sea como una continuación deliberada del pasado, como el pasado en el presente, como una parte de la propia identidad, ya es otra cosa diferente a la cultura invocada. El problema aparece cuando, una vez separada de sí misma en el sentido de vivencia y considerada a distancia, la cultura, ahora ya patrimonio, puede llegar a convertirse en un elemento de información que se hace llegar a los otros, ya sean escolares, turistas, gente mayor, o cualquier otro consumidor de patrimonio.

El turismo se puede considerar como una actividad que contribuye a la re-significación de la naturaleza, por ejemplo, del mar, y a la re-significación de la cultura, por ejemplo, lo marítimo, estimulando ciertos aspectos del proceso de patrimonialización. De ahí que, por ejemplo, la maritimidad ${ }^{1}$ de una población o región, se esté incorporando como un

1. Maritimidad es un neologismo propuesto por los antropólogos marítimos franceses: «Parler de maritimité, c'est inviter a réfléchir sur les constructions sociales et culturelles qui ont été édifiées par les groupes humains pour organiser leurs relations à la mer, pour sén protéger, pour la socialiser, pour la baliser, pour l'aimer. Ces constructions s'ancrent bien entendu dans le profondeur historique, mais en même temps, elles sont évolutives. S'interroger sur la maritimité contemporaine, c’est réfléchir sur les rapports entre le présent et le passé, dans une perspective de compréhension des reconversions actuelles du maritime, mises en relation avec les aspirations et les besoins profonds de notre société» (Peron \& J. Rieucau, 1996:14). Para nosotros, y por encima de esta definición, la maritimidad será la condición de ser marítimo, de estar vinculado y sentirse parte de lo marítimo. 
elemento más del discurso patrimonializador a través del cual se crea el catálogo que se ofrece al turismo cultural.

En las definiciones más al uso, el patrimonio se ve como el resultado de un proceso de incorporación de un cierto tipo de valor referido al pasado al producir alguna cosa nueva en el presente que recorre al pasado y por tanto podemos considerarlo como una nueva forma de producción cultural, una nueva industria que da valor al pasado en el presente (Kirshenblatt-Gimblett, 2001). Se trata de un proceso de reconfiguración de valores y significados referidos a elementos sociales, culturales o naturales del pasado (Mármol, Frigolé, Narotzky, 2010) que en último caso también pueden serlo del presente; por ejemplo, cuando hacemos referencia a la diversidad de especies que históricamente aún están presentes hoy en día en nuestros mares y que, por tanto, habrá que conservar patrimonializándolas; o de las múltiples formas tradicionales de preparación de esas especies que los pescadores han utilizado en el pasado y que ahora también se intentan patrimonializar.

Cuando el valor incorporado es valor de uso es cuando hablamos, entre otras, de la dimensión identitaria que alcanza el patrimonio. Cuando el valor es de cambio es cuando hablamos del proceso de mercantilización de la cultura transformada en patrimonio. Pero el valor patrimonial de los bienes, ya sean materiales o inmateriales, nunca es una propiedad inherente a ellos sino un juicio que se hace acerca de ellos, un discurso patrimonializador. Por tanto, el concepto de valor patrimonial no tiene mucho sentido, porque lo único que da valor e intenta mantenerlo es ese discurso patrimonializador. Así, la bien conocida expresión francesa de la mise en valeur, utilizada frecuentemente como sinónimo de proceso de patrimonialización, es un buen indicador de esa tendencia a un posible sesgo economicista del término, y ello a pesar que se hace referencia al valor -valor de uso- y no al precio -valor de cambio. Si por el contrario se nos dice que esa mise en valeur solo está haciendo referencia a la valoración no económica sino al valor cultural, histórico o identitario, y no al precio de mercado, entonces lo que está ocurriendo es que cae en una posición tecnocrática o cientificista de la cultura en la que ciertos expertos, técnicos culturales o científicos sociales, son los que determinan cuáles son los elementos de la cultura popular o tradicional susceptibles de ser sometidos a un proceso de producción patrimonial que les permita entrar en la categoría valorada de patrimonio cultural como valor de uso.

\section{PATRIMONIO PESQUERO, GASTRONOMÍA Y TURISMO CULTURAL}

Las prácticas gastronómicas son una materialización de la cultura de un país, de una región, de una localidad. En ellas se reflejan valores, pautas socioculturales y relaciones de poder. De esta forma, las cocinas, las comidas, son vías activas a través de las cuales podemos entrar en contacto directo con otra cultura, o vías a través de las cuales el turista cambia el rol de espectador por el de actor. Sin embargo, la comercialización de 
productos culturales gastronómicos locales en contexto turístico la mayor parte de las veces se limita a la lógica económica, olvidando el interés cultural de mantener y difundir la herencia gastronómica de un territorio concreto, su cultura gastronómica. Es de este modo como las prácticas gastronómicas de las clases populares acaban convirtiéndose en objetos susceptibles de patrimonialización por su poder identitario, tal y como Isabel González ya mostró con el ejemplo del gazpacho entre otros (González, 1995).

La cocina está de moda y los chefs aún más. La cocina se basa en la gastronomía y la gastronomía es una parte muy importante de la cultura de un pueblo. La UNESCO ha definido la gastronomía como parte integrante del patrimonio cultural inmaterial de un país, a la vez que se ha incorporado, cada vez más activamente, en las políticas culturales y de promoción del turismo. En su manifestación actual en nuestra sociedad, la gastronomía, representada paradigmáticamente por los chefs más mediáticos, galvaniza todo lo que el arte expresaba antes de su agotamiento contemporáneo: la singularidad de un individuo creador y su búsqueda de la perfección, pero también la experiencia sensorial del espectador. Si las artes cultas del siglo XX entraron en crisis es precisamente por haber negado al espectador la experiencia de los sentidos (Puigverd, 2008). Pero en la comida es obligatorio apelar a los sentidos. Históricamente primero se hizo persiguiendo el efecto contrario, desactivando ciertos sentidos que el estado de conservación de ciertos alimentos activaba negativamente, como en el caso de los alimentos de origen marino con una conservación muy precaria. De ahí, por ejemplo, la introducción generalizada en la Edad Media de las especies procedentes de Oriente o anteriormente la elaboración del garum $^{2}$ (2) por parte de los romanos. Una vez más o menos controlados esos efectos negativos, hoy, la vista, el olfato, el gusto, el tacto y el oído aparecen en acción, jugando cada uno su papel en ciertas y específicas (re)elaboraciones culinario-gastronómicas. La vista con presentaciones artísticas de los platos con formas y colores sublimes; el gusto con juegos de contrastes o maridajes inalcanzables, impensables hasta ahora; el tacto con el distanciamiento de los cubiertos en relación a ciertos alimentos que hay que comerlos con las manos con el correspondiente idílico retorno a los orígenes naturales; y el oído, con sorbetes y crujientes que son, y han de ser, bien sonoros.

La escisión de la realidad se produce cuando una tendencia gastronómica como la tecnoemotiva de Ferrán Adrià se entrega hasta tal punto a la idea de potenciar el papel de los sentidos que éstos, para captarla, deben subordinarse a la mente, en la línea de la tesis de Harris en Bueno para comer, bueno para pensar. Y es así como, a modo de reacción

2. Los expertos nos dicen que si actualmente alguien intentara hacer el garum tal y como lo hacían los romanos sería totalmente imposible, atendiendo a las pautas culturales gastronómicas actuales, poder ingerirlo, sobre todo por la sensación olfativa y gustativa que desprendería. Sin embargo, encontramos variada oferta de preparados elaborados en base a pescado, anchoas principalmente, que remiten a este importante alimento de los romanos, principalmente a sus legiones desplazadas fuera de la metrópoli para las cuales, el garum aseguraba una importante aportación proteínica además de un producto típicamente romano. 
anti-emotiva, el chef Santamaría intentó, poco antes de morir, reconducir la situación afirmando que de lo se trata es de comer, no de pensar: "cuando la modernidad pierde la olla, la tradición convierte la olla en bandera" (Puigvert, 2008).

La Gastronomía, puede tomar la forma, entre otras, de una cultura del pescado, entendiendo ésta en el sentido de entramado cultural, tal y como Martílo plantea: "conjunto formado por todos aquellos elementos (culturales), y los agentes sociales que los crean y se sirven de ellos" (Martí, 2004). Es por eso mismo que las prácticas gastronómicas también podemos verlas como una materialización de la cultura de un país y así la gastronomía se está incorporando cada vez más activamente a las políticas culturales y de promoción del turismo. Sin embargo, demasiado a menudo, la comercialización de tradiciones gastronómicas locales se limita a la lógica económica, olvidando el interés cultural y hasta identitario, de mantener y difundir la herencia y la tradición gastronómica de un territorio concreto, en el sentido que el escritor Josep Pla expresaba: la cocina es el paisaje puesto en la cazuela.

El proceso de patrimonialización de los peces y el pescado que se produce en el Espai del Peix y que aquí analizamos, creemos es un ejemplo singular de patrimonialización -valoración- por atribución al objeto -los peces y el pescado- de un valor sui generis o extraordinario -patrimonio natural y gastronomía-, que siempre es concebido como ajeno al valor económico (cultura) pero que se intenta que se sume a él con el objetivo explícito de hacer más rentable la actividad pesquera profesional, tal y como hoy ésta se desarrolla en un contexto híper-turistificado como el de la Costa Brava. Actualmente en Cataluña los colectivos relacionados con la actividad marítimo-pesquera atraviesan una profunda crisis institucional, económica y social. Uno de los peligros manifiestos para la pesca como actividad vinculada al sector primario, generadora de riqueza y de puestos de trabajo para muchas personas de las poblaciones del litoral es que está siendo repensada desde diversas perspectivas con la finalidad de encontrar salidas a esa crisis. La pesca, a consecuencia de ello, puede pasar a ser considerada y tratada simultáneamente como una actividad productiva así como un objeto cultural para consumo turístico ${ }^{3}$,

3. Ver el Decreto 87/2012, de 31 de julio, sobre la pesca-turismo, el turismo pesquero y acuícola y las demostraciones de pesca en aguas marítimas y continentales de Cataluña. Sobre todo los artículos siguientes: Artículo 2.a. Difundir el patrimonio, las tradiciones, los oficios, la gastronomía y la cultura vinculados a la actividad de la pesca, el marisqueo y la acuicultura y el entorno del sector. Art.2.b. Promover y revalorizar los productos de la pesca, el marisqueo y la acuicultura, incluida la compra y la degustación de pescado y marisco maridados con otros productos de proximidad. 2.c. Divulgar las técnicas pesqueras, las artes y aparejos de pesca y la evolución social, económica y tecnológica del sector. 2.d. Facilitar la adquisición de merchandising, material educativo y objetos de recuerdo vinculados a la actividad de la pesca, el marisqueo y la acuicultura. 
asociándola a categorías como lo primitivo, lo tradicional, lo irracional, lo insostenible, lo exótico o lo turístico. De ahí que los procesos de producción patrimonial asociados a la pesca, presentados bajo la forma de objetos de consumo dirigidos al turismo, pueden no estar ayudando, o pueden no ayudar en un futuro, a mejorar el estatus de la propia actividad, su sostenibilidad, ni a mejorar las relaciones entre pesca y turismo que no han dejado de ser conflictivas en los últimos años, debido sobre todo a que el turismo náutico ha entrado en escena como un nuevo usuario del mar compitiendo por unos mismos recursos con los pescadores.

El patrimonio cultural asociado al mundo de la pesca está siendo uno de los últimos en incorporarse a la escena de los estudios del Patrimonio (Carbonell, 2008, 2010; Florido, 2003; Rubio, 2010). En Palamós esta labor se hace simultáneamente en una doble dirección. Por una parte, en relación al patrimonio natural, mueble, inmueble e intangible, mediante el proceso de producción patrimonial que toma como substrato la cultura marítimo-pesquera de la localidad. Este proceso se realiza en los equipamientos culturales creados en la población durante los últimos diez años y que son el Museu de la Pesca, el Documare (Centro de Documentación de la Pesca y el Mar de Palamós) y la Càtedra d'Estudis Marítims. Por otra parte, y en relación al patrimonio intangible, el proceso de patrimonialización utiliza como sustrato la cultura del pescado y se lleva a cabo en el Espai del Peix. Cultura marítimo-pesquera y cultura del pescado, dos caras de una misma moneda sometidas a un proceso de producción patrimonial pensado para crear productos y discursos patrimoniales dirigidos fundamentalmente al turismo cultural y gastronómico.

En el caso de la Costa Brava, al igual que en otros lugares donde el turismo está ya fuertemente implantado, el turismo cultural aparece como un producto complementario, cuando no sustitutorio, del hasta ahora hegemónico sol y playa. Estas ofertas se dirigen a segmentos sociales, nacionales o extranjeros, con cierto nivel educativo y adquisitivo que buscan algo diferente y especial más allá de la oferta turística clásica y masiva en temporada veraniega. La preocupación básica reside en el peligro que se presenta al tratar aspectos de un sector productivo primario -la pesca- desde una perspectiva y unos discursos propios del sector terciario -turismo y patrimonio- que siguen lógicas diferentes, o solo desde la perspectiva económico-empresarial, sino y sobre todo, desde la perspectiva socio-cultural. Tal y como puso de manifiesto un pescador: nosotros vivimos del mar y ellos pretenden vivir en el mar.

\section{EL MARCO INSTITUCIONAL DONDE SE PRODUCE EL PROCESO DE PRODUCCIÓN PATRIMONIAL MARÍTIMO}

El discurso propio del proceso de producción patrimonial marítimo-pesquero en Palamós se produce en un contexto institucional muy preciso que creemos oportuno describir brevemente para de este modo llegar a comprender mejor las características 
del mismo, su oportunidad y su viabilidad, sobre todo en momentos de crisis como los actuales donde casi todas las poblaciones turísticas del litoral han empezado una carrera desenfrenada por patrimonializar todo lo propio relativo al mar.

Palamós es una pequeña villa del litoral mediterráneo catalán ubicada en el corazón de la Costa Brava, en la que, sobre todo a nivel municipal y desde una perspectiva cultural, ya hace más de veinte años que se trabaja intensamente por recuperar y recrear su maritimidad o carácter marítimo. Este interés apareció cuando ya se empezaba a vislumbrar el agotamiento del modelo turístico tradicional basado en el modelo de sol y playa. Se trataba de ir reelaborando y potenciando su propia identidad como pueblo históricamente viviendo del mar, ya fuera a través de la pesca, del comercio marítimo y en las últimas décadas del turismo de masas. La identidad marítima de Palamós se empezó a trabajar ampliando conocimientos y programando ofertas culturales vinculadas a las actividades marítimas que siempre habían conformado su vida como comunidad de pescadores, de puerto comercial y de recreo y zona turística de litoral y que en demasiadas ocasiones eran desconocidas, o habían sido relegadas, a un segundo plano en la vida de la villa.

El primer equipamiento cultural que se creó en este sentido fue el Museo de la Pesca de Palamós en la primavera del 2001. Anterior al momento de su creación había tenido lugar un largo debate entre los agentes patrimonializadores sobre qué forma debería tomar ese museo, si debía denominarse museo, ya que en algunos lugares del mediterráneo en los años ochenta se empezaron a construir grandes equipamientos culturales como acuarios, o se empezaban a reformular o rediseñar antiguos museos temáticos vinculados a lo marítimo. Después de desestimar una idea inicial de creación de un gran equipamiento tipo Ictiópolis, donde idealmente estuvieran representados la mayor parte de los ámbitos relativos a todo lo marítimo, se decidió hacer una apuesta más realista, aunque hay que reconocer que fue muy arriesgada para aquel momento y sin precedentes en el ámbito mediterráneo, para la creación de un museo dedicado a la pesca marítima. Si ponemos el énfasis en el carácter innovador y arriesgado de la propuesta es porque en aquellos años lo marítimo en general y lo pesquero en particular aún no habían llegado a hacerse presentes con identidad propia en el entorno cultural local y regional. Así, la propuesta de dedicar monográfica y específicamente un museo a la pesca, o a los pescadores, no fue una idea bien entendida en aquel momento; además del hecho que en todo el mediterráneo occidental no existía, y sigue sin existir en la actualidad, ningún museo de esas características.

Después de muchas vicisitudes inherentes a la realización de un proyecto innovador como ese, en un contexto político local y regional poco acostumbrado a intervenciones culturales en medio turístico, y menos aún en el ámbito portuario, se logró consensuar un proyecto museográfico que se creyó factible y ajustado a las posibilidades de la población 
y del momento. El esquema inicial del proyecto era el de un típico museo temático, en este caso dedicado a la pesca marítima, pero que desde un principio se abrió a todo tipo de actividades que complementaban el discurso de sus salas y ampliaban enormemente sus objetivos culturales. Es en este contexto que al amparo de la institución municipal Museo de la Pesca, e inmediatamente después del momento de su inauguración, se empezaron a crear otras instituciones vinculadas estrechamente al Museo que compartían fines y medios pero se especializaban en diferentes ámbitos. Por una parte, dada la consolidación creciente de los trabajos de investigación que ya se habían realizado para elaborar el proyecto del museo, se trabajó en la creación del Centro de documentación de la Pesca y el Mar (Documare) para dar respuesta a las inquietudes y demandas que desde diferentes ámbitos del mundo de la educación, se venían planteando al museo a partir del mismo momento de su inauguración. Por ejemplo, unos de los primero usuarios de ese conocimiento recogido y sistematizado sobre el mundo de la pesca y de los pescadores, fue el requerido para la realización de trabajos de investigación de alumnos de educación primaria y secundaria, así como universitarios o investigadores amateurs o particulares, que a partir de ese mismo momento se transformaron en sus principales usuarios. En resumen, Documare se ha transformado en el receptáculo donde se depositan, sistematizan y se ofrecen al público interesado todos los conocimientos e informaciones que se han ido generando a través de las diferentes actividades que se realizan en el marco del proyecto patrimonializador global vinculado al mar y la pesca en Palamós y la Costa Brava.

Otra institución patrimonializadora que se creó, simultáneamente y en paralelo al Documare, fue la Catedra de Estudios Marítimos (CEM), adscrita a la Universitat de Girona (UdG) y creada gracias a un convenio entre la Universidad y el Ayuntamiento de Palamós. La CEM fue el resultado natural de la continua y creciente vinculación y colaboración que el Museo tuvo con la UdG desde los primeros momentos de diseño del proyecto museográfico. La CEM, como institución universitaria, tiene como misión vincular la universidad con el territorio, específicamente en todos aquellos temas relacionados con el mar y lo marítimo. Si bien su objetivo fundacional no es docente, su actividad se centra en la promoción y divulgación del conocimiento, en la aplicación del mismo a la realidad económica, social y cultural y por consiguiente colabora y da apoyo a otras instituciones relacionadas como la Cofradía de pescadores, con la que también tiene firmado un convenio de colaboración, así como con el propio Ayuntamiento. Resultado de la actividad desarrollada por la CEM ha sido, por ejemplo, la realización de investigaciones y estudios relativos a la Historia del Puerto de Palamós ${ }^{4}$, de la Cofradía de Pescadores 5 , de la Historia de Pesca en la región de la Costa Brava, de algunos Oficios

\footnotetext{
4. Alegret, J.L. (2005).

5 Alegret, J.L. y A. Garrido (2004).
} 
tradicionales, además de estudios sobre la Memoria histórica asociada a la actividad pesquera, los movimientos migratorios de los pescadores, las fuentes y bases estadísticas de la actividad pesquera, los carpinteros de ribera, etc., y en los últimos tres años los estudios relativos al proyecto de creación de una Reserva Marina de Interés Pesquero frente a Palamós. La gran mayoría de estos trabajos han culminado con la publicación de libros monográficos, cuadernos técnicos, dossiers y todo tipo de publicaciones que ayudan a incrementar cualitativa y cuantitativamente el patrimonio marítimo y pesquero de la población.

Por lo que respecta al trabajo vinculado a la patrimonialización de la Memoria Histórica, y con la colaboración de todas las instituciones vinculadas al Museo se han realizado algunas experiencias de formato innovador y muy exitosas, con el objetivo de hacer participar a la población en ese trabajo, lo que está creando un fuerte arraigo identitario vinculado a las diferentes manifestaciones del proceso de producción patrimonial. Hacemos referencia a dos actividades, una con una vida de más de diez años como las Conversaciones de Taberna y otra de reciente creación como Imagenes que hacen hablar. Ambas actividades programadas mensual y bimensualmente se fundamentan en la participación de personas de la región vinculadas al mar y que se transforman en los protagonistas de las actividades como facilitadores de información y conocimiento.

En el caso de las Conversaciones y como su nombre indica, se trata de invitar en torno a la mesa de una taberna, a un grupo reducido de personas vinculadas vitalmente a un tema concreto para que presenten sus experiencias y discutan entre ellos, haciendo también participar al público asistente, entre el que siempre se encuentran más personas con conocimientos y memoria histórica sobre ese mismo tema. Esta actividad cultural vinculada estrechamente a la investigación sobre la memoria histórica ha podido ser transformada en un bien patrimonial mediante la filmación de más de 300 horas realizadas a lo largo de los más de once años de existencia de esa actividad y que están a disposición de investigadores y personas interesadas en el Documare. En el caso de las Imágenes que hacen hablar la actividad se centra en la proyección pública y abierta de imágenes fotográficas, históricas o recientes, que el público va llenando de contenido y explicando polifónicamente mediante comentarios espontáneos mientras las observa, transformándose en una fuente inagotable de información almacenada en la memoria histórica de cada uno de los participantes. A la información y conocimiento obtenido de este modo se le da el mismo tratamiento que a las Conversaciones siendo otro de los procesos patrimonializadores locales más valorados por la propia población en el sentido identitario.

Por último, y casi como resultado lógico de la evolución de las instituciones culturalespatrimonializadoras presentadas hasta ahora, se ha creado la última y más polivalente e innovadora de todas ellas, el Espai del Peix. Este equipamiento cultural, que abrió sus 
puertas a principios de 2012, está ubicado en un lugar estratégico del puerto pesquero y ha sido diseñado para complementar las actividades realizadas desde el Museo, la CEM y el Documare. Podemos definir como su objetivo central la patrimonialización de la cultura marítima asociada a todo el proceso de captura, comercialización y consumo del pescado que se realiza en Palamós y la región de la Costa Brava por la flota pesquera con base en ese puerto.

\section{EL ESPAI DEL PEIX COMO INSTITUCIÓN PATRIMONIALIZADORA}

El Espai del Peix ${ }^{6}$ puede considerarse como el resultado lógico de la evolución de los demás equipamientos, entre otras razones porque viene a llenar un vacío que existía en ellos, y que cada vez se iba haciendo más patente. En los últimos años, un número creciente de visitantes del Museo de la Pesca, o de asistentes a las diversas actividades organizadas por la CEM, ponían de manifiesto su interés por conocer más sobre el tipo de pescado capturado en Palamós, sus diversas formas de preparación y sobre todo por la posibilidad de degustarlo. Es en este sentido que la propia experiencia nos mostró lo que la teoría museológica y ciertas corrientes de moda en el ámbito gastronómico nos vienen anunciando desde hace tiempo en relación a que las sensaciones y las emociones empezaban a ser los nuevos protagonistas en esas instituciones. A algunas de estas inquietudes que manifestaban los visitantes ya se les intentaba dar respuesta a través de la organización de actividades específicas por parte del Museo o la CEM. Algunas de ellas son los itinerarios explicativos por el muelle comercial o la dársena pesquera para conocer el tipo de embarcaciones que desarrollan su actividad desde ese puerto, las visitas comentadas a la lonja del pescado para conocer el proceso de comercialización en primera venta mediante la subasta, o bien la visita al mercado de pescado para apreciar la colorida y variada exposición y venta de las especies capturadas y los precios que éstas alcanzan. En paralelo a estas actividades también se ofrecían una gran variedad de conferencias, cursos, seminarios, talleres o charlas, que desde la CEM, Documare o el Museo, se organizaban en relación a la extracción, comercialización, preparación y consumo del pescado capturado en Palamós. A pesar de toda esta enorme oferta existente, sin embargo faltaba un lugar desde donde se pudiera poner en valor todo lo relativo a las especies pescadas, sus propiedades nutricionales y la enorme riqueza cultural asociada a su preparación y consumo. De ahí surgió la idea de crear un espacio cultural propio para el pescado que complementara al museo como espacio cultural del pescador.

Desde un punto de vista del proceso de patrimonialización el Espai del Peix se propuso un doble objetivo que lo convertía, cuando menos, en singular: actuar simultánea e indistintamente como agente patrimonializador sobre dos de los cuatro ámbitos clásicos de manifestación del patrimonio: el natural y el intangible, quedando parcialmente fuera

6. http://www.espaidelpeix.org/index.php/es.html 
los ámbitos inmueble y mueble, que ya estos encuentran su lugar preferente en los otros dos equipamientos: el Museo y el Documare.

El objetivo principal del Espai del Peix no es la presentación de elementos culturales como objetos de consumo -las especies pescadas- sino la reubicación de esos objetos en un contexto más amplio que desborde el estricto ámbito económico asociado al consumo turístico, hasta llegar a jugar el papel de reforzamiento de la identidad local a través del saber de los pescadores, la historia pesquera de la población y en definitiva la potenciación de la totalidad de la cultura marítimo-pesquera de la zona.

Por una parte, al actuar como agente patrimonializador de la naturaleza, el Espai del Peix lo hace programáticamente mediante la puesta en valor de ciertas especies marinas - peces, crustáceos o mariscos- que por diversos motivos han sido relegadas del mapa económico, social y cultural, hasta llegar a casi desaparecer de la memoria colectiva, de la cultura popular y de la tradición gastronómica, sobre todo entre la población no vinculada a la actividad pesquera. Por otra parte el Espai del Peix actúa como agente patrimonializador en el ámbito del patrimonio inmaterial o intangible al interpretar, en el triple sentido de investigar, conservar y activar (Florido, 2003), el patrimonio cultural gastronómico asociado a la presencia, representación y consumo de ese conjunto diferenciado de especies.

Las especies objeto de patrimonialización en el Espai del Peix, por regla general y no siempre, sólo se encuentran en los mercados locales, ya que no entran en los circuitos comerciales más allá de la población y su ámbito de influencia y suelen poseer denominaciones locales diferentes en ciertas poblaciones de la costa. Además suelen ser especies desconocidas por el público ajeno al sector pesquero y por tanto, hasta ahora, ni se solían comprar ni consumir, pues sólo estaban presentes en el acervo y recetas populares de las familias de los pescadores y de ciertos grupos locales muy restringidos.

Desde el punto de vista del patrimonio intangible, los saberes y las técnicas de los propios pescadores relativos al conocimiento y las prácticas sobre las formas de preparación y consumo de esas especies, son el elemento central del proceso de patrimonialización que se realiza en el Espai del Peix. Sin embargo, hay que puntualizar que la voluntad de patrimonializar este ámbito de la cultura marítimo-pesquera no se debe a la desaparición del oficio de pescador o de la transformación de la pesca profesional en una actividad productiva marginal o residual, como ha sido el caso de la minería en Asturias (Córdoba y García, 2005) o de las trementinaires del Pirineo (Frigolé, 2005), ambas sometidas actualmente a procesos de patrimonialización. Por el contrario, la decisión de activar patrimonialmente este tipo de especies y la cultura alimentaria asociada a ellas ${ }^{7}$ se debe

7. Recordar que un proceso de patrimonialización de la cultura de los pescadores ya se estaba haciendo, desde hace más de una década, mediante el Museo de la Pesca, el Documare y la CEM. 
a cambios, podríamos denominar adaptativos, que se han ido produciendo en el propio oficio de pescador y que han hecho cambiar el papel que jugaban esas especies en la ingesta diaria de los pescadores durante su jornada laboral, hasta hacerlas casi desaparecer junto a todo el conocimiento asociado a su preparación. Los cambios que se han producido han sido, el acortamiento de la jornada laboral de los pescadores y por tanto la disminución del tiempo pasado a bordo, lo que ha provocado que la preparación del rancho durante la jornada laboral haya cambiado profundamente hasta llegar a relegar la utilización gastronómica a bordo de esas especies y las prácticas culinarias a ellas asociadas. Por otra parte, la mejora de las condiciones técnicas para la preparación de los alimentos a bordo, con la creación de espacios para la ubicación de una cocina-comedor han provocado que durante las últimas décadas se haya producido un cambio muy sustancial por lo que se refiere a la dieta de los pescadores durante la jornada laboral en la que el pescado y su preparación ya no juega el papel central que antes jugaba.

Tanto a nivel programático como práctico, el principal objetivo que se propone el Espai del Peix como equipamiento cultural innovador es el de llegar a poder dotar al "peix de poc preu" - pescado de poco precio-, de un valor patrimonial que hasta ahora no tenía, sobre todo en comparación con otras especies que sí lo tienen, como es el caso paradigmático de la Gamba de Palamós (Aristeus antenatus). Se trata así de crear un discurso patrimonializador en torno a un conjunto reducido de especies marinas que, aun siendo conocidas, pescadas, preparadas y consumidas histórica y tradicionalmente por los pescadores y sus familias y ciertos grupos reducidos de gente del litoral, ahora pasen a formar parte del patrimonio natural e inmaterial de la zona, mediante un proceso de producción patrimonial centrado exclusivamente en esas especies y por lo tanto excluyendo de esa acción a la gran mayoría de especies comercializadas en la lonja de la Cofradía. Sin embargo, ello no quiere decir que estas especies de poco precio no tuvieran, ni sigan teniendo hoy día, un valor cultural muy arraigado entre los pescadores y sus familias ya que siempre han jugado un papel central en sus actividades, pues los pescadores siempre han sabido cómo pescarlas, prepararlas y consumirlas diariamente y

8. La gamba de Palamós, desde hace más de una década, se está viendo sometida a un constante proceso de valorización, sobre todo debido al papel estratégico que esta especie tiene para el sector pesquero local al ocupar más del $50 \%$ del valor total de sus capturas. La valorización se realiza mediante diferentes acciones como el Menú de la Gamba, la Marca de Garantía y un Plan de Gestión. El Menú de la Gamba fue promovido por el Ayuntamiento de Palamós y una asociación de restauradores de Palamós y de la zona de la Bahía. Por otra parte, con fecha 24 de noviembre de 2009 se creó la Marca de Garantía de la Gamba de Palamós, con informe favorable de la Generalitat de Catalunya, expediente 0005S-3531/2009 y marca de registro de la propiedad industrial referencia 2947362/4, publicada en el BOP 13/4/11. La Marca de Garantía la han promovido la Cofradía de Pescadores conjuntamente con el Ayuntamiento y la colaboración de la Universitat de Girona. Además, en la actualidad, ya está muy avanzada la creación de un Plan de Gestión de la Gamba de Palamós promovido por la Cofradía de Pescadores con el apoyo científico de la Universitat de Girona y el Centre de Estudis del Mar (CSIC) de Barcelona, plan que deberá ser aprobado y promulgado por el Ministerio de Agricultura, Alimentación y Medio Ambiente. 
así lo han hecho de forma generalizada hasta tiempos muy recientes, por lo que podemos decir que siguen formando parte integral de su cultura.

El proceso de producción patrimonial de las especies de poco precio empieza dando a conocer su existencia, el papel que han jugado en el consumo productivo a bordo, sus propiedades nutricionales, así como la gran variedad de preparaciones gastronómicas conocidas. Es de este modo como estas especies y la cultura asociada a ellas que actúa como sustrato patrimonial, pueden llegar a alcanzar la categoría de bienes patrimoniales que, sin perder su valor de uso, adquieren un nuevo valor de cambio, ahora también como bienes patrimoniales naturales e inmateriales, sin que ello haya provocado, de momento, un incremento considerable de su valor comercial en la primera venta en la subasta de la lonja aunque ya se empiezan a percibir algunos cambios.

En el proceso de producción del discurso patrimonial sobre el Peix de poc preu intervienen ciertos expertos, técnicos culturales y científicos de las ciencias naturales y sociales que son los encargados de definir y justificar ese valor añadido cultural sobre el que se apoya el discurso de legitimación patrimonial elaborado desde sus respectivas disciplinas, trabajando conjuntamente y guiados por un mismo objetivo. De ahí la importancia que desde un primer momento tuvo la creación del Consejo Asesor del Espai. Su cometido, junto al de los técnicos culturales fue el de determinar los elementos de la cultura popular y tradicional susceptibles de ser incorporados al discurso patrimonializador, para de ese modo posibilitar su incorporación a la categoría valorada de patrimonio cultural. Para poder lograr ese objetivo han elaborado un discurso que permite transformar especies, técnicas y saberes asociados a la captura, preparación y consumo de esas especies en un bien patrimonial susceptible de ser introducido con bastante éxito en el mercado de bienes culturales, además de simultáneamente dotar a ese patrimonio, de una dimensión identitaria que una parte de la población de Palamós ha reconocido como propia.

Actualmente en el Espai del Peix se están ofreciendo bienes culturales del tipo: Talleres gastronómicos, Sesiones de demostración y degustación de la cocina del peix de poc preu, Show Cookings, Sesiones gastronómico-literarias, además de una Exposición permanente formada por audiovisuales y plafones dedicados al pescado desde todos los ámbitos que actúan a modo de Centro de Interpretación del pescado. Estos bienes culturales se ofrecen bajo diversos formatos que incluyen así mismo visitas guiadas realizadas desde el Centro de interpretación de la Pesca y desde el Puerto de Palamós. El Espai del Peix nació vinculado al Museo de la pesca como un elemento para complementarlo pero formando parte de la misma red de equipamientos entrelazados y con una finalidad patrimonializadora. Por ese motivo su orientación inicial se quiso que continuara siendo la museística, pero dado el amplio conjunto de posibilidades que se ofrecían en este nuevo equipamiento, se pensó que se podía y se debía llegar a ofrecer algo más que un nuevo museo del pescado, que como la propia denominación nos indica, no hubiera tenido 
demasiado sentido. Es así como el Espai del Peix se diseñó para que simultáneamente fuera un Centro de interpretación de la pesca de Palamós, a la vez que un Aula Gastronómica del pescado capturado por la flota pesquera de Palamós y un Taller de Degustación de esa gastronomía?.

La visita guiada al Espai del Peix se inicia con la visita a la Lonja de pescado y la visualización de la subasta en directo desde un mirador creado con ese objetivo y que a su vez sirve de sala de recepción para la visita. Para poder realizar en un mismo espacio las actividades propias de un Centro de Interpretación, una Aula Gastronómica y un Taller de Degustación se diseñó un espacio polivalente en el que se combinan recursos y medios expositivos y pedagógicos de un museo, un aula, una cocina y un observatorio / mirador. En la antesala de ese espacio y actuando como sala de recepción, hay unos posters que reproducen la cartografía de los caladores frecuentados por la flota de pesca de Palamós y la tipología básica de las embarcaciones que operan en esos caladores. En ese mismo lugar, ocupando un papel central, se ha colocado una pantalla de grandes dimensiones donde se proyecta un documental de introducción al Espai del Peix. Este documental tiene un doble objetivo; por una parte presentar la importancia de la alimentación a través de productos marinos, la larga tradición gastronómica de Cataluña en relación al consumo y la preparación de pescado y por otra, y en definitiva, sensibilizar al público acerca de la riqueza patrimonial existente al entorno de esta fuente alimentaria. Por otra parte el documental tiene como objetivo crear una situación liminal que induzca al visitante a un tránsito entre su llegada desde la calle y su incorporación al equipamiento como protagonista-actor de la visita. El recurso expositivo central del Espai del Peix son 14 plafones horizontales que ocupan la superficie de cada una de las 14 mesas del equipamiento ${ }^{10}$. En ellos se presentan, utilizando técnicas museográficas convencionales, los contenidos básicos de las explicaciones que articulan las visitas guiadas. A su vez, estas mesas son las que sirven simultáneamente para las actividades propias del aula, así como

9. En el estatuto fundacional del Espai del Peix se propusieron programáticamente como objetivos que debían guiar toda la actividad, los siguientes: potenciar la cocina del pescado fresco de la costa como elemento básico de la dieta mediterránea; fomentar el conocimiento del mundo de la pesca para revalorizar el oficio de pescador; fomentar los hábitos de consumo saludables; ser un foro de reflexión, debate y conocimiento para el estudio de la captura, preparación del pescado; contribuir a alcanzar una gestión sostenible de los recursos naturales marinos; difundir el proceso que va desde de la captura hasta el consumo del pescado; luchar contra la obesidad infantil; facilitar los parámetros necesarios para valorar el puerto de Palamós, histórica, social y económicamente; promocionar los productos gastronómicos relacionados con el consumo del pescado local y ofrecer una experiencia sensorial a todos los usuarios.

10. Los temas tratados a través de esta exposición horizontal corresponden a los contenidos de las 14 mesas que ocupan el espacio central de la sala y que hacen referencia a los siguientes contenidos: 1. El pescado blanco, $2 \mathrm{El}$ pescado azul, 3. El marisco, 4 Una cocina con historia, 5. El pescado en el mercado, 6. El pescado en conserva, 7. La preparación del pescado, 8. Las técnicas de cocción, 9. Los ingredientes, 10. Los utensilios, 11. La cocina de los pescadores, 12. La cocina del pescado en Cataluña, 13. La cocina del pescado en el mundo, 14. El pescado, un alimento sano y nutritivo. 
para las degustaciones. Una gran cocina actúa a modo de tarima y pizarra, apoyada por 2 pantallas, cámaras y megafonía de soporte, y transmiten en directo las actividades de los cocineros o de las personas que desde la cocina desarrollan sus explicaciones. La cocina además es el espacio natural de trabajo para los cocineros o invitados encargados de los Show cooking dedicados a la cocina tradicional marinera, la cocina étnica, la alta cocina de chefs de prestigio, la cocina de a bordo, o cualquiera de las campañas de divulgación sobre las especies marinas que se capturan en la zona y de la gastronomía asociada a ellas.

Tal y como se ha comentado anteriormente y dado que Palamós ya tenía una larga tradición gastronómica vinculada a los productos del mar, se decidió que el discurso patrimonializador relativo al pescado que se realiza desde el Espai del Peix se centrara fundamentalmente en aquellas especies que tienen menor valor comercial ${ }^{11}$, ya que las especies estrella como la gamba, la merluza, el rape, la cigala, por mencionar sólo algunas ${ }^{12}$, ya poseían un valor de cambio consolidado que las convertían en no prioritarias para ser patrimonializadas.

Con la finalidad de identificar los pasos dados y los actores que han intervenido e intervienen en el proceso de producción patrimonial que se realiza en el Espai del Peix utilizaremos la propuesta que desde la antropología económica hace Franquesa cuando afirma que si el objeto guardado, protegido, patrimonializado, no existía como tal bien patrimonial con anterioridad al inicio del proceso, el valor de tal objeto deberá analíticamente ser entendido como el resultado del trabajo de guardar. Así, el trabajo o proceso de guardar se puede descomponer en tres operaciones: singularización, valorización y preservación (Franquesa, 2010). Estas tres operaciones no se pueden considerar aisladamente más que a efectos analíticos, puesto que en la práctica son inseparables y cada una requiere de las otras.

En el caso del Espai del Peix, la singularización del objeto patrimonial, vista como la primera parte del proceso de producción patrimonial, consta a su vez de tres etapas sin

11. A efectos patrimonializadores, en el Espai del Peix se considera pescado de poco precio a aquellas especies que perteneciendo al inventario de recursos marinos (peces, crustáceos o mariscos) extraídos tradicional e históricamente por los pescadores profesionales de Palamós, sin embargo en el proceso de primera venta mediante subasta no alcanzan precios significativos o relevantes. Este es el caso, entre otros de: Maira (Micromesitius poutassou); Pota-voladora ( Illex coindetii); Congrio (Conger conger); Pintaroja (Scyliorhinus canucula); Brótola (Phycis blennoides); Anchoa (Engraulis encrasicolus; Sardina (Sardina pilchardus); Raya (Raja sp.); Caballa (Scomber scombrus); Gambita blanca (Plesionika sp.); Merluza pequeña (Merluccius merluccius); Pulpo (Eledone cirrhosa); Besugo pequeño (Pagellus acarne); Araña (Trachinus draco); Barracuda (Sphyraena sphyraena).

12. Estas especies son: la gamba roja (Aristeus antennatus) con un $38,67 \%$ del valor de los ingresos brutos anuales; la merluza (Merluccius merluccius) 7,92\%; la cigala (Nephrops norvegicus) 7,85\%; la bacaladilla (Micromesistius poutassou) 5,26\%; el rape (Lophius piscatorius) 5,25\%; el calamar (Loligo reynaudi) $3,00 \%$ y la anchoa (Engraulis encrasicolus) con un 2,49\% sobre el total de capturas. Fuente: Cofradia de Pescadores de Palamós, 2006. 
solución de continuidad. Por una parte, se trata de singularizar aquellas especies que actualmente alcanzan unos precios de venta muy bajos y que por tanto tienen poco valor comercial, o sea, las que "casi no tienen precio", a pesar de que siempre han tenido un valor socio-cultural entre los pescadores y cierta parte de la población que tradicionalmente las conoce, las utiliza y las consume. Por otra parte, se trata de singularizar los métodos y artes de pesca utilizados en la captura de esas especies. Este aspecto del proceso ya se estaba realizando desde hace más diez años en el Museo de la Pesca de Palamós donde los sistemas de pesca que se han utilizado tradicionalmente para pescar esas especies juegan un papel central en el discurso museográfico y se transforman y reconocen como bienes patrimoniales. Por último, se trata de singularizar esas especies desde la perspectiva de la cultura gastronómica que la cocina tradicional mantiene para la preparación y consumo de esas especies. Una cultura gastronómica que no se limita al conocimiento y la praxis de los propios pescadores para la preparación de sus ranchos de a bordo sino que se extiende a la tradición gastronómica de una parte más amplia de la sociedad local y regional.

Por su parte, la valorización de ese objeto patrimonial se produce por la mediación del equipamiento cultural Espai del Peix, que proponemos considerarlo como un modelo híbrido entre un museo, una sala de exposiciones, un centro de interpretación, un aula gastronómica, un taller de cocina y un mercado alimentario. Cada uno de estos ámbitos cumple la función de producir valores específicos patrimoniales asociados a las especies y sus ecosistemas -patrimonio natural-; su proceso de captura -patrimonio material e inmaterial-; así como al conjunto de su gastronomía -patrimonio inmaterial-.

La preservación, como última parte del proceso de patrimonialización que se realiza en el Espai del Peix, es el mecanismo crucial para poder explicar de qué modo los objetos patrimonializados llegan a adquirir una dinámica de valor inversa a la de las mercancías, o sea que a más tiempo transcurrido, más valor alcanzan. Valor que en este caso está asociado a la preservación de las especies, la diversidad biológica y el ecosistema marino. De ahí la importancia de considerar los peces, no el pescado, como patrimonio natural.

Es de este modo cómo los discursos patrimonializadores que se producen en este equipamiento neo-museográfico, deben procurar dar forma de valor al objeto, es decir, facilitar la lectura del objeto como un objeto de valor tanto natural como cultural, de modo que la preservación debe consistir en la adecuación del objeto patrimonializado al discurso de valor (Franquesa, 2010).

Mención especial merece uno de los instrumentos fundamentales que, en paralelo al proyecto del Espai del Peix e íntimamente ligado a él, se comenzó a implementar para trabajar la preservación de las especies marinas anteriormente mencionadas y que ahora son consideradas como patrimonio natural marítimo-pesquero y que hace referencia al proyecto de creación de una Reserva Marina de interés pesquero en la zona de las Illes 
Formigues. La creación de esta reserva inicialmente la propuso en 2009 la Cofradía de pescadores de Palamós al Ministerio de Agricultura y Pesca del gobierno del Estado, con el apoyo del Ayuntamiento de Palamós. Todos los solicitantes vieron la propuesta como un elemento más de ese amplio proceso de producción patrimonial asociado a la actividad pesquera que se viene realizando desde el puerto de Palamós y que hace referencia al elemento más relevante como son la preservación futura de las especies sin las cuales el proyecto no tiene sentido. El objetivo inicial del proceso de solicitud de creación de la reserva marina por parte de la Cofradía fue la de proteger uno de los caladeros de pesca tradicionalmente utilizados por los pescadores artesanales de Palamós. La protección se había hecho necesaria dado que la zona se estaba viendo sometida a una presión desmesurada por parte de los diferentes agentes sociales que regularmente se hacen presentes en ella, aparte de los pescadores profesionales, tales como pesca submarina, navegación recreativa, pesca deportiva y pescadores furtivos tanto submarinos como de superficie.

La zona a proteger propuesta por la Cofradía de pescadores correspondía inicialmente a un área de aproximadamente $500 \mathrm{Ha}$ alrededor de unos islotes denominados Illes Formigues que se hallan a menos de una milla de la línea de costa, frente a Palamós. Este calador tradicional de la pesca artesanal los pescadores lo utilizan cuando se dan malas condiciones meteorológicas al no poder desplazarse mar adentro, actuando de este modo como un calador-refugio, así como zona de concentración y crecimiento de los alevines por encontrarse cerca de la costa en aguas relativamente poco profundas. Sin embargo, durante la última década, sobre todo en época estival y fines de semana, esta zona se ha ido transformando en impracticable para los pescadores artesanales, tanto por la disminución de capturas debido al elevado aumento del esfuerzo de pesca por parte de los pescadores deportivos y submarinistas, como por la sobreocupación de la superficie marina por una multitud de embarcaciones deportivas recreativas que han hecho del lugar una zona muy solicitada para desarrollar sus actividades de recreo.

Desde el primer momento, el Museo de la Pesca y las demás instituciones vinculadas a la protección del patrimonio marítimo de Palamós consideraron que la propuesta de creación de la reserva marina iniciada por la Cofradía de Pescadores se ajustaba perfectamente y era un elemento fundamental de ese amplio esfuerzo patrimonializador de la pesca artesanal en general y de las especies por ella capturadas. Sin embargo, la especificidad de tratarse de un intento de preservar patrimonio natural bajo la forma de especies y territorio marino, que a su vez estaba siendo disputado por diferentes actores con intereses y lógicas muy dispares, pronto demostró que el proceso de producción patrimonial en este caso debería producirse por unos caminos muy distintos a los hasta ahora utilizados. La primera consecuencia de este hecho ha sido la importante polarización de la sociedad y de las instituciones de Palamós al posicionarse abiertamente 
a favor o en contra del proceso de patrimonialización de esa parte de la naturaleza, lo que llevó en 2011 al bloqueo total del proyecto después de fuertes presiones políticas, campañas en los medios de comunicación y manifestaciones callejeras en contra de la creación de la reserva.

Aparte de la especificidad del caso de la reserva marina, los actores que han intervenido en la producción de los diferentes discursos patrimonializadores de las dos primeras fases de singularización y valorización han sido muchos y muy diversos. En este sentido hay que destacar la participación de científicos de las ciencias naturales: ictiología y ecología; de las ciencias de la salud: médicos y nutricionistas; además de científicos sociales, que desde la perspectiva antropológica e histórica, también han estado presentes y participado desde un principio en el proceso de singularización de las especies, las artes de pesca, la gastronomía y en general todos los aspectos asociados a la cultura popular sobre esas especies. Por otra parte, también han participado los técnicos del Museo de la Pesca y los museógrafos encargados de elaborar las diferentes exposiciones. Por último, en la parte relativa a la gastronomía, junto a los anteriores también han participado gastrónomos, profesionales de la cocina y pescadores-rancheros.

En relación a la última parte relativa a la preservación del patrimonio natural marino, y más allá del fracaso del proyecto de la Reserva, los esfuerzos los han realizado también biólogos, expertos en la gestión de pesquerías y de reservas marinas, además del papel muy relevante jugado por los propios pescadores y los políticos de las diferentes administraciones, unos posicionándose a favor y otros en contra, además de los miembros de algunos movimientos ecologistas y asociaciones con posicionamientos paradójicamente también dispares.

\section{CONCLUSIÓN}

La patrimonialización de la cultura y de la naturaleza supone procesos de puesta en valor de elementos seleccionados y marcados que conducen a nuevas conceptualizaciones de la realidad social, tal y como en nuestro caso ocurre con ciertas especies marinas pescadas así como con sus formas tradicionales de preparación para ser consumidas a bordo. Es de ese modo como las formas tradicionales de pesca artesanal y las prácticas gastronómicas de los pescadores pueden acabar convirtiéndose en objetos susceptibles de patrimonialización, entre otros por su poder identitario.

Partiendo del principio que el valor patrimonial nunca preexiste al objeto patrimonializado sino que es el resultado de un proceso discursivo de producción patrimonial y que la cultura siempre es la materia prima de la que se alimenta el patrimonio, hemos mostrado el modo como una institución cultural patrimonializadora como el Espai del Peix de Palamós, que se apoya en la cultura marítima de los pescadores, crea un discurso propio en torno a un conjunto de especies que tienen un valor comercial mínimo, hasta llegar 
a transformarlas en un objeto patrimonial que se ofrece para el consumo del turismo cultural bajo múltiples formatos. Es de este modo como el proceso de producción patrimonial del pescado de poco precio lo podemos considerar como una nueva modalidad de producción cultural que toma la forma de las recetas tradicionales de los pescadores. La acción patrimonializadora realizada en el equipamiento cultural descrito se centra en el carácter singular de unas especies marinas, que si bien generalmente son desconocidas por el público ajeno a la cultura marítima, siempre han formado parte de la cultura de los pescadores locales, ya fuera bajo la forma de capturas para ser comercializadas, o como especies dedicadas al auto-consumo mediante repertorios gastronómicos muy diversos que son los que conforman la cocina marinera tradicional local. Es así como especies, artes y técnicas de pesca y recetas tradicionales marineras son transformadas en bienes patrimoniales mediante un discurso patrimonializador elaborado desde diversas miradas científicas que son las que dotan de legitimidad a todo el proceso. 


\section{REFERENCIAS BIBLIOGRÁFICAS}

Alegret, Joan Lluis (2003) El Port de Palamós. Memòria d’un centenari 1902-2002. Barcelona: Generalitat de Catalunya. Ports de la Generalitat.

Alegret, Joan Lluis y Garrido, Alfons (2004) Història de la Confraria de Pescadors de Palamós. Palamós: Confraria de Pescadors de Palamós.

Appadurai, Arjun (2001) La modernidad desbordada. Dimensiones culturales de la Globalización. Buenos Aires: TRILCE, FCE.

Carbonell, Eliseu (2008) "Veure l'invisible: Patrimoni cultural immaterial marítim". Drassana, 16, pp. 28-39.

Carbonell, Eliseu (2010) "Patrimoni marítim i usos socials de la platja de Sant Pol de Mar”. Revista d'Etnologia de Catalunya, 35, pp. 230-233.

Córdoba, Matilde y García, José Luis (2010) "Cuando la naturaleza se convierte en patrimonio, o los usos políticos de los paraísos naturales". En Camila del Mármol, Joan Frigolé y Susana Narotzky (eds.). Los Lindes del Patrimonio. Consumo y valores del pasado. Barcelona: Icaria-ICA, pp. 191-210.

Doyon, Sabrina (2008) "La construcción social del espacio: el caso de la reserva de la biosfera de Ria Lagartos, Yucatán, México”. En Oriol Beltrán, José. J. Pascual e Ismael Vaccaro (coord.) Patrimonialización de la naturaleza: el marco social de las políticas ambientales. Donostia: Ankulegui, FAAEE, pp. 289-306.

Florido del Corral, David (2003) "Hacia una patrimonialización de la cultura pesquera en Andalucía”. Boletín del Instituto Andaluz del Patrimonio Histórico, 11(44), pp. 30-33.

Franquesa, Jaume (2010) "Una aproximación al patrimonio desde la antropología económica: la patrimonialización como guardar”. En Camila del Mármol, Joan Frigolé y Susana Narotzky (eds.). Los Lindes del Patrimonio. Consumo y valores del pasado. Barcelona: Icaria-ICA, pp. 39-57.

García-Allut, Antonio (2003) "La pesca artesanal, el cambio y la patrimonialización del conocimiento”. Boletín del Instituto Andaluz del Patrimonio Histórico, 11(44), pp. 74-83.

González Turmo, Isabel (1995) Comida de rico, comida de pobre. Los hábitos alimenticios en el occidente andaluz (siglo XX). Sevilla: Universidad de Sevilla, Secretariado de Publicaciones.

Mármol, C.; Frigolé J. y Narotzky S. (2010) "Introducción. Los lindes del patrimonio. Consumo y valores del pasado". En Camila del Mármol, Joan Frigolé y Susana Narotzky (eds.). Los Lindes del Patrimonio. Consumo y valores del pasado. Barcelona: Icaria-ICA. Martí, Josep. (2004) "Antropòlegs sense cultura ». Quaderns de l'Institut Català d'Antropologia 19, pp. 35-54. 
Martí, Miquel (2005) "El patrimoni marítim i els museus de Catalunya", Drassana, 13, pp. 48-56.

Pereira, Dionisio (2009) "Una visión estratégica del patrimonio marítimo: comparativa entre Catalunya, Euskadi y Galicia”. Itsas Memoria. Revista de Estudios Marítimos del País Vasco, nº6, p.15.

Perón, Françoise y Rieucau, Jean (1996) La maritimité aujourd'hui.

Prats, Llorenç (2006) "La mercantilización del patrimonio: entre la economía turística y las representaciones identitarias". Boletín del Instituto Andaluz del Patrimonio Histórico, 58, pp. 72-80.

Puigverd, Antoni (2008) “Cuando la modernidad pierde la olla”. La Vanguardia 9-6-2008 Rubio-Ardanaz, Juan Antonio (2010) "El concepto de patrimonio y de cultura: gestión museística e íconos públicos en el País Vasco". Itsas Memoria. Revista de Estudios Marítimos del País Vasco, 6, pp. 1-34.

Santana, Agustín y Pascual, José (2003) "Pesca y turismo: conflictos, sinergias y usos múltiples en Canarias”. Boletín del Instituto Andaluz del Patrimonio Histórico, 11(44), pp. 86-97. 